Bond University

Research Repository

\title{
2.4-km Run and 20-m Multistage Fitness Test Relationships in Law Enforcement Recruits After Academy Training
}

Lockie, Robert G.; Hernandez, Javier; Moreno, Matthew R. ; Dulla, Joe J.; Dawes, Jay; Orr, Rob Marc

Published in:

Journal of Strength and Conditioning Research

DOI:

10.1519/JSC.0000000000003489

Licence:

Other

Link to output in Bond University research repository.

Recommended citation(APA):

Lockie, R. G., Hernandez, J., Moreno, M. R., Dulla, J. J., Dawes, J., \& Orr, R. M. (2020). 2.4-km Run and 20-m Multistage Fitness Test Relationships in Law Enforcement Recruits After Academy Training. Journal of Strength and Conditioning Research, 34(4), 942-945. https://doi.org/10.1519/JSC.0000000000003489

\section{General rights}

Copyright and moral rights for the publications made accessible in the public portal are retained by the authors and/or other copyright owners and it is a condition of accessing publications that users recognise and abide by the legal requirements associated with these rights.

For more information, or if you believe that this document breaches copyright, please contact the Bond University research repository coordinator. 
A Follow-up Research Note: 2.4-km Run and 20-m Multistage Fitness Test Relationships in Law Enforcement Recruits Post-Academy Training

\section{Brief Running Head: Post-Academy 2.4-km Run and 20MSFT Relationships}

Robert G. Lockie ${ }^{1}$, Javier A. Hernandez ${ }^{1}$, Matthew R. Moreno ${ }^{1}$, Joseph M. Dulla ${ }^{2}$ J. Jay Dawes ${ }^{3}$, Robin M. Orr ${ }^{4}$.

${ }^{1}$ Department of Kinesiology, California State University, Fullerton, Fullerton, CA, USA.

${ }^{2}$ Recruit Training Unit, Training Bureau, Los Angeles County Sheriff's Department, Los Angeles, CA, USA.

${ }^{3}$ Department of Health and Human Performance, Oklahoma State University, Stillwater, OK, USA.

${ }^{4}$ Tactical Research Unit, Bond University, Robina, Qld, Australia.

$\bowtie$ Robert Lockie

California State University, Fullerton

Department of Kinesiology

800 N State College Blvd

Fullerton, CA 92831

USA

Phone (international): $\quad+1657-278-3316$

Email: $\quad$ rlockie@fullerton.edu 


\section{ABSTRACT}

The 2.4-km run and 20-m multistage fitness test (20MSFT) are common aerobic fitness tests in law enforcement. Previous research analyzed relationships between these tests in recruits, and indicated limited transferability due to disparate demands (direction changes, running intensity). However, the correlations between 2.4-km run and 20MSFT in recruits postacademy training may be different, where recruits should be fitter and able to complete highintensity running efforts. This study documented changes in and relationships between the 2.4$\mathrm{km}$ run and 20MSFT in law enforcement recruits post-academy training. Retrospective analysis on six academy classes (276 males, 50 females) from one agency was conducted. The 20MSFT and 2.4-km run were completed pre- and post-academy training. Estimated $\dot{\mathrm{V}}_{2 \text { max }}$ was derived from 2.4-km run time and the 20MSFT shuttle number. Paired-samples t-tests ascertained whether the 2.4-km run and 20MSFT improved post-academy. Correlations and linear regression derived relationships between the 2.4-km run and 20MSFT. Recruits improved in the 2.4-km run and 20MSFT $(p<0.01)$. There were significant correlations between the 2.4$\mathrm{km}$ run and 20MSFT for all recruits $(r=-0.49)$, males $(r=-0.48)$, and females $(r=-0.29)$. However, the regression equations for all recruits $\left(r^{2}=0.24\right)$, males $\left(r^{2}=0.23\right)$ and females $\left(r^{2}\right.$ $=0.08)$ were low. The results suggested there were disparate aspects to the $2.4-\mathrm{km}$ run and 20MSFT in law enforcement recruits post-academy. Even though aerobic fitness improved, there are likely other aspects important to the 20MSFT not developed during academy (changeof-direction ability, high-intensity running). This could have impact the between-test relationship.

Key words: 1.5-mile run; academy training; cardiovascular fitness; maximal aerobic capacity; police; tactical 


\section{INTRODUCTION}

Law enforcement can be a physically challenging profession, and a key physiological requirement for officers is aerobic fitness. Aerobic fitness may help an officer if they need to complete a number of demanding tasks in succession, or sustain on effort for an extended duration (5). Additionally, aerobic fitness could reduce the risk of cardiovascular disease (10), of which there is a high incidence in law enforcement officers (22). Two of the most common tests used to measure aerobic capacity in law enforcement recruits are the $2.4-\mathrm{km}$ (1.5-mile) run and the 20-meter multistage fitness test (20MSFT) $(6,13)$.

There are strengths and limitations to the $2.4-\mathrm{km}$ run and 20MSFT. The 2.4-km run, while providing a valid measure of aerobic fitness (8), typically involves an internal pacing strategy (13). This may not match the intensity required in many law enforcement tasks (e.g. suspect pursuit), where the pace is externally governed (16). The 20MSFT also provides valid measure of aerobic fitness (17), and places greater demands on high-intensity running and includes the continual requirement to decelerate, change direction and accelerate. This test has an external stimulus that increases pace, and may be more appropriate as it relates to policing tasks (13). However, the constant direction changes can prove stressful (14), and individuals that cannot keep pace could be ejected from the 20MSFT even if they have not reached their maximal aerobic capacity (20). Nonetheless, better performance in the $2.4-\mathrm{km}$ run and 20MSFT has been linked to academy graduation in law enforcement recruits, which indicates the practical application of both tests $(7,19,21)$.

This led Lockie et al. (13) to investigate the relationships between the 2.4-km run and 20MSFT in law enforcement recruits. This was done to determine whether the two tests measured similar capacities, and to illustrate whether certain training practices could be appropriate if either test was used as an entry requirement. The results indicated that although the 2.4-km run had significant relationships with the 20MSFT for all recruits $(r=-0.57)$, males 
$(r=-0.55)$, and females $(r=-0.60)$, the predictive regression equations were all low (all recruits $r^{2}=0.32$; males $r^{2}=0.30$; females $r^{2}=0.37$ ). These data indicated limited transferability between the two tests. Additionally, the estimated maximal aerobic capacity $\left(\dot{\mathrm{V}}_{2 \mathrm{max}}\right)$ from 2.4-km run was greater than that from the 20MSFT, which may suggest recruits were relatively better at the 2.4-km run. Lockie et al. (13) did note that the relationships between the $2.4-\mathrm{km}$ run and 20MSFT may change after academy training, when the recruits should be more fit. If the relationships between the tests are stronger, this may suggest that recruits not only improved their ability to run for distance, but they can operate at a higher running intensity.

This follow-up research note investigated the relationships between 2.4-km run times and 20MSFT shuttles in law enforcement recruits post-academy training. It was hypothesized that 2.4-km run, 20MSFT, and estimated $\dot{\mathrm{V}}_{2 \max }$ derived from both these tests would improve for recruits following academy training. It was further hypothesized that the relationships between the 2.4-km run and 20MSFT would be stronger than that found by Lockie et al. (13).

\section{METHODS}

\section{Experimental Approach to the Problem}

Data for the 2.4-km run and 20MSFT were recorded pre- and post-academy, and estimated $\dot{\mathrm{V}}_{2 \max }$ were derived. Firstly, data were analyzed to ascertain whether the $2.4-\mathrm{km}$ run time and 20MSFT improved after academy training. The relationship between the two tests postacademy was investigated with Pearson's correlations and linear regression.

\section{Subjects}

Retrospective analysis on recruits from six academy classes from one agency was conducted. This sample comprised 326 recruits (age: $26.60 \pm 4.95$ years; height: $1.74 \pm 0.09 \mathrm{~m}$; body mass: $80.51 \pm 14.67 \mathrm{~kg}$ ), including 276 males (age: $26.57 \pm 5.01$ years; height: $1.76 \pm 0.07 \mathrm{~m}$; body 
mass: $83.08 \pm 13.18 \mathrm{~kg}$ ) and 50 females (age: $26.72 \pm 4.67$ years; height: $1.62 \pm 0.07 \mathrm{~m}$; body mass: $66.32 \pm 14.49 \mathrm{~kg}$ ). The six training cohorts completed their academy within a calendar year in southern California. Based on the archival nature of this analysis, the institutional ethics committee approved the use of pre-existing data (HSR-17-18-370).

\section{Procedures}

The data were collected by staff working for one agency. All recruits graduated from the 22week academy conducted by this agency. Schedules and physical training sessions varied between classes due to logistic arrangements. Nonetheless, all classes adhered to the standards expected by the state's governing body (Peace Officers Standards and Training), where a minimum of 36 physical training sessions were required (15). All six academy classes completed more sessions than the minimum. For pre-testing, the 20MSFT was completed 3-10 days before the first day of academy, while the 2.4-km run was completed within the first week. The 20MSFT was conducted outdoors on an asphalt surface at the agencies' training facility. Testing typically occurred between the hours of 0900-1400 depending on recruit availability. The 2.4-km run was conducted between the hours of 0500-0700 depending on scheduled physical training sessions during academy, and was completed on an outdoor dirt track. For post-testing, the 2.4-km run and 20MSFT were completed on separate days in the final weeks of academy depending on the class schedule, typically between 0500-1200. The 20MSFT was completed on a concrete surface, while the $2.4-\mathrm{km}$ run was completed on the same dirt track.

\section{0-m Multi-Stage Fitness Test (20MSFT)}

For the 20MSFT, recruits ran back and forth between two lines spaced $20 \mathrm{~m}$ apart, indicated by markers. The running speed was standardized via pre-recorded auditory beeps played from an iPad device (Apple Inc., Cupertino, California) connected to a portable speaker (ION Block 
Rocker, Cumberland, Rhode Island) located in the center of the running area. The test was terminated when the recruit was unable to reach the lines twice in a row in accordance with the beeps, or via voluntary cessation, and was scored according to the total number of completed shuttles. $\dot{\mathrm{V}} \mathrm{O}_{2 \max }$, measured in milliliters per $\mathrm{kg}$ body mass per minute $\left(\mathrm{ml} \cdot \mathrm{kg}^{-1} \cdot \mathrm{min}^{-1}\right)$, was estimated based on the table from Ramsbottom et al. (17).

\section{4-km Run}

Recruits completed six laps around the track at the agencies' training facility as quickly as possible. Run time was recorded on a stopwatch to the nearest $0.10 \mathrm{sec}$, and reported in min: s. $\dot{\mathrm{V}} \mathrm{O}_{2 m a x}$ was estimated for male and female recruits via the following equations (8):

Male $\dot{\mathrm{V}}_{2 \max }\left(\mathrm{ml} \cdot \mathrm{kg}^{-1} \cdot \mathrm{min}^{-1}\right)=91.736-(0.1656 \times$ body mass $)-(2.767 \times 2.4 \mathrm{~km}$ run time in min).

Female $\dot{\mathrm{V}}_{2 \max }\left(\mathrm{ml} \cdot \mathrm{kg}^{-1} \cdot \mathrm{min}^{-1}\right)=88.020-(0.1656 x$ body mass $)-(2.767 \times 2.4 \mathrm{~km}$ run time in min).

\section{Statistical Analysis}

Statistical analyses were processed using the Statistics Package for Social Sciences (Version 24; IBM Corporation, New York, USA). Descriptive data (mean \pm SD) were calculated for all recruits, males, and females for the 2.4-km run, 20MSFT, and estimated $\dot{\mathrm{VO}}_{2 \max }$ from each test pre- and post-academy. Paired samples t-tests $(p<0.05)$ were used to compare the pre- and post-academy data, and percentage changes were also calculated. This analysis was conducted to confirm that performance in both tests improved for both sexes. Following this, Pearson's correlations $(p<0.05)$ and linear regression scatter plots calculated relationships between 2.4$\mathrm{km}$ run time and 20MSFT shuttle score, for all recruits and each sex. The correlation strength was designated as: an $r$ between 0 to \pm 0.3 was considered small; \pm 0.31 to \pm 0.49 , moderate; 
\pm 0.5 to \pm 0.69 , large; \pm 0.7 to \pm 0.89 , very large; and \pm 0.9 to \pm 1 , near perfect for relationship prediction (9).

\section{RESULTS}

The pre- and post-academy descriptive data for the 2.4-km run and 20MSFT are shown in Table 1. Recruits (all combined, males, and females) significantly improved in 2.4-km run time, 20MSFT shuttles, and the estimated $\dot{\mathrm{VO}}_{2 \max }$ after academy training.

\section{***INSERT TABLE 1 ABOUT HERE***}

With regards to the correlation analysis, the $2.4-\mathrm{km}$ run time had moderate relationships with the 20MSFT shuttles for all recruits $(r=-0.49)$ and males $(r=-0.48)$, and a small relationship with females $(r=-0.29)$. Each relationship indicated that a faster $2.4-\mathrm{km}$ run related to a greater 20MSFT shuttle number. The $r^{2}$ values from the regression equations for all recruits $\left(r^{2}=0.24\right.$; Figure 1$)$, males $\left(r^{2}=0.23\right.$; Figure 2$)$ and females $\left(r^{2}=0.08\right.$; Figure 3$)$ were all low.

\footnotetext{
***INSERT FIGURE 1 ABOUT HERE***

***INSERT FIGURE 2 ABOUT HERE***

***INSERT FIGURE 3 ABOUT HERE***
}

\section{DISCUSSION}

This research note was a follow-up to Lockie et al. (13), and analyzed relationships between the 2.4-km run and 20MSFT in law enforcement recruits post-academy training. Firstly, all recruits improved their aerobic fitness as measured by the $2.4-\mathrm{km}$ run and 20MSFT, and 
estimated $\dot{\mathrm{V}}_{2 \max }$ from both of these tests. Interestingly, the improvements were substantial (31-37\% increase) in the 20MSFT. Continuous running, calisthenics, and circuit training is a focus of physical training for this agency (11), and the data suggests that this training was effective in improving aerobic fitness. Learning effects could have also contributed to the improvements seen in the 20MSFT (1). Nevertheless, the recruits in this study had superior aerobic fitness to those from Lockie et al. (13).

Similar to Lockie et al. (13), there were significant relationships between the 2.4-km run and 20MSFT in this research note. However, the strength of the correlations for all recruits $(r=-0.57$ vs. -0.49$)$, males ( $r=-0.55$ vs. -0.48$)$, and females ( $r=-0.60$ vs. -0.29$)$ were all lower in the current study. Further, the $r^{2}$ values from this data indicated that only $8-24 \%$ of the variance was explained between these tests. This is much lower than that presented by Lockie et al. (13) (explained variance $=30-37 \%$ ). Furthermore, the estimated $\dot{\mathrm{V}} \mathrm{O}_{2 \max }$ from $20 \mathrm{MSFT}$ was lower than that calculated from the $2.4-\mathrm{km}$ run, which implies the recruits still performed relatively better in the $2.4-\mathrm{km}$ run (13). These results collectively indicate that relationships between the 2.4-km run and 20MSFT were weaker following academy training. This is counter to the hypothesis, and suggests there are disparate aspects to the 2.4-km run and 20MSFT in law enforcement recruits post-academy training.

Although correlation does not suggest causation, there are several reasons why these results may have occurred. As stated, long, continuous running is a staple of physical training for this agency (11). While this may develop aerobic fitness (and contribute to the improvements in the 2.4-km run and 20MSFT), there are other qualities important to the 20MSFT (but less so for the 2.4-km run) that may not be improved. This is important, as these qualities could also enhance law enforcement job tasks. For example, the ability to change direction is important to effective performance in the 20MSFT $(13,14)$. However, change-ofdirection training is generally not a focus for law enforcement recruits. Change-of-direction 
ability can also be impacted by strength and power (18), and these qualities are also not often a focus of training for this agency (11). Improving the ability to change direction could impact not just the 20MSFT, but job performance in tasks such as a foot pursuit as well (2). Highintensity running is also stressed in the 20MSFT, and this quality needs to be specifically trained (3). Developing high-intensity running would be beneficial for recruits given many of their job tasks demand high-intensity, externally-paced activity (16).

It is notable that the predictive relationship for females was much weaker in this research note than for Lockie et al. (13). Female recruits generally perform poorer in fitness tests compared to males $(2,4,6,12)$. This issue is compounded by the 'one-size-fits-all' training model used by this agency (11), whereby all recruits are expected to perform the same training exercises regardless of individual fitness. Female recruits may be working at a relatively higher intensity for the same exercise when compared to male recruits, resulting in earlier onset of fatigue and thus less time spent performing effective high-intensity efforts. This could then have led to the weak relationships displayed between the $2.4-\mathrm{km}$ run and 20MSFT.

\section{PRACTICAL APPLICATIONS}

In addition to aerobic training, law enforcement training staff should attempt to incorporate high-intensity running and change-of-direction training during academy. Developing these qualities could improve not only the 20MSFT, but specific job tasks such as suspect pursuit. Staff should also consider the training intensities performed by female recruits, as an earlier onset of fatigue could limit the effective high-intensity efforts performed in training.

\section{REFERENCES}

1. Aandstad, A, Holme, I, Berntsen, S, and Anderssen, SA. Validity and reliability of the 20 meter shuttle run test in military personnel. Mil Med 176: 513-518, 2011. 
2. Bloodgood, AM, Dawes, JJ, Orr, RM, Stierli, M, Cesario, KA, Moreno, MR, Dulla, JM, and Lockie, RG. Effects of sex and age on physical testing performance for law enforcement agency candidates: Implications for academy training. J Strength Cond Res: doi:10.1519/jsc.0000000000003207, in press.

3. Cavar, M, Marsic, T, Corluka, M, Culjak, Z, Cerkez Zovko, I, Müller, A, Tschakert, G, and Hofmann, P. Effects of 6 weeks of different high-intensity interval and moderate continuous training on aerobic and anaerobic performance. J Strength Cond Res 33: 44$56,2019$.

4. Cesario, KA, Dulla, JM, Moreno, MR, Bloodgood, AM, Dawes, JJ, and Lockie, RG. Relationships between assessments in a physical ability test for law enforcement: Is there redundancy in certain assessments? Int J Exerc Sci 11: 1063-1073, 2018.

5. Dawes, JJ, Lindsay, K, Bero, J, Elder, C, Kornhauser, C, and Holmes, R. Physical fitness characteristics of high vs. low performers on an occupationally specific physical agility test for patrol officers. $J$ Strength Cond Res 31: 2808-2815, 2017.

6. Dawes, JJ, Orr, RM, Flores, RR, Lockie, RG, Kornhauser, C, and Holmes, R. A physical fitness profile of state highway patrol officers by gender and age. Ann Occup Environ Med 29: doi:10.1186/s40557-017-0173-0, 2017.

7. Dawes, JJ, Lockie, RG, Orr, RM, Kornhauser, C, and Holmes, RJ. Initial fitness testing scores as a predictor of police academy graduation. J Aust Strength Cond 27: 30-37, 2019.

8. George, JD, Vehrs, PR, Allsen, PE, Fellingham, GW, and Fisher, AG. VO2max estimation from a submaximal 1-mile track jog for fit college-age individuals. Med Sci Sports Exerc 25: 401-6, 1993.

9. Hopkins, W.G. A scale of magnitude for effect statistics, 2013. Available from: www.sportsci.org/resource/stats/index.html. Accessed January 9, 2016. 
10. Kodama, S, Saito, K, Tanaka, S, Maki, M, Yachi, Y, Asumi, M, Sugawara, A, Totsuka, K, Shimano, H, Ohashi, Y, Yamada, N, and Sone, H. Cardiorespiratory fitness as a quantitative predictor of all-cause mortality and cardiovascular events in healthy men and women: A meta-analysis. JAMA 301: 2024-2035, 2009.

11. Lockie, RG, Dawes, JJ, Balfany, K, Gonzales, CE, Beitzel, MM, Dulla, JM, and Orr, RM. Physical fitness characteristics that relate to Work Sample Test Battery performance in law enforcement recruits. Int $J$ Environ Res Public Health 15: doi:10.3390/ijerph15112477, 2018.

12. Lockie, RG, Dawes, JJ, Orr, RM, Stierli, M, Dulla, JM, and Orjalo, AJ. An analysis of the effects of sex and age on upper- and lower-body power for law enforcement agency recruits prior to academy training. J Strength Cond Res 32: 1968-1974, 2018.

13. Lockie, RG, Dawes, JJ, Moreno, MR, Cesario, KA, Balfany, K, Stierli, M, Dulla, JM, and Orr, RM. Relationship between the 20-m multistage fitness test and 2.4-km run in law enforcement recruits. $J$ Strength Cond Res: doi:10.1519/jsc.0000000000003217, in press.

14. Moreno, MR, Lockie, RG, Kornhauser, CL, Holmes, RJ, and Dawes, JJ. A preliminary analysis of the relationship between the multistage fitness test and 300-m run in law enforcement officers: Implications for fitness assessment. Int J Exerc Sci 11: 730-738, 2018.

15. Peace Officer Standards and Training. Training and Testing: Specifications for Learning Domain \#32 Lifetime Fitness, 2013. Available from: https://post.ca.gov/post_docs/training/trainingspecs/LD32.doc. Accessed July 18, 2019. 
16. Plat, MJ, Frings-Dresen, MH, and Sluiter, JK. A systematic review of job-specific workers' health surveillance activities for fire-fighting, ambulance, police and military personnel. Int Arch Occup Environ Health 84: 839-857, 2011.

17. Ramsbottom, R, Brewer, J, and Williams, C. A progressive shuttle run test to estimate maximal oxygen uptake. Br J Sports Med 22: 141-144, 1988.

18. Sheppard, JM and Young, WB. Agility literature review: Classifications, training and testing. J Sports Sci 24: 919-932, 2006.

19. Shusko, M, Benedetti, L, Korre, M, Eshleman, EJ, Farioli, A, Christophi, CA, and Kales, SN. Recruit fitness as a predictor of police academy graduation. Occup Med 67: $555-561,2017$.

20. Thomas, A, Dawson, B, and Goodman, C. The yo-yo test: reliability and association with a 20-m shuttle run and VO(2max). Int J Sports Physiol Perform 1: 137-149, 2006.

21. Tomes, CD, Sawyer, S, Orr, R, and Schram, B. Ability of fitness testing to predict injury risk during initial tactical training: a systematic review and meta-analysis. Injury Prevention: doi:10.1136/injuryprev-2019-043245, 2019.

22. Zimmerman, FH. Cardiovascular disease and risk factors in law enforcement personnel: A comprehensive review. Cardiol Rev 20: 159-166, 2012.

\section{FIGURE LEGEND}

Figure 1: Regression scatter plot for all recruits between the 2.4-km run and 20MSFT.

Figure 2: Regression scatter plot for male recruits between the 2.4-km run and 20MSFT.

Figure 3: Regression scatter plot for female recruits between the 2.4-km run and 20MSFT. 
Table 1: Pre- and post-academy descriptive data (mean \pm SD; percentage change) for all, male, and female LEA recruits in the $2.4-\mathrm{km}$ run and $20 \mathrm{MSFT}$.

\section{4-km Run}

Estimated

min: $\mathrm{s}$

$\dot{\mathrm{V}} \mathrm{O}_{2 \max }$
20MSFT

Estimated

No. of shuttles

$\dot{\mathrm{V}} \mathrm{O}_{2 \max }$

\begin{tabular}{|c|c|c|c|c|}
\hline \multicolumn{5}{|c|}{ All Recruits $(\mathrm{N}=326)$} \\
\hline Pre & $12: 02 \pm 1: 21$ & $44.68 \pm 4.51$ & $50 \pm 16$ & $34.27 \pm 5.40$ \\
\hline Post & $11: 20 \pm 1: 15^{*}$ & $46.46 \pm 4.50^{*}$ & $68 \pm 22 *$ & $39.38 \pm 6.34^{*}$ \\
\hline$\%$ Change & -6 & 4 & 36 & 15 \\
\hline \multicolumn{5}{|c|}{ Males $(n=276)$} \\
\hline Pre & $11: 50 \pm 1: 17$ & $45.32 \pm 4.38$ & $51 \pm 16$ & $34.71 \pm 5.58$ \\
\hline Post & $11: 12 \pm 1: 14^{*}$ & $47.00 \pm 4.39 *$ & $70 \pm 22 *$ & $40.03 \pm 6.37^{*}$ \\
\hline$\%$ Change & -5 & 4 & 37 & 15 \\
\hline \multicolumn{5}{|c|}{ Females $(\mathrm{n}=50)$} \\
\hline Pre & $13: 04 \pm 1: 10$ & $41.14 \pm 3.53$ & $42 \pm 9$ & $31.86 \pm 3.43$ \\
\hline Post & $12: 08 \pm 1: 02 *$ & $43.46 \pm 3.91^{*}$ & $55 \pm 17^{*}$ & $35.80 \pm 4.84^{*}$ \\
\hline$\%$ Change & -7 & 6 & 31 & 12 \\
\hline
\end{tabular}

* Significantly $(p<0.01)$ different from the pre-test. 


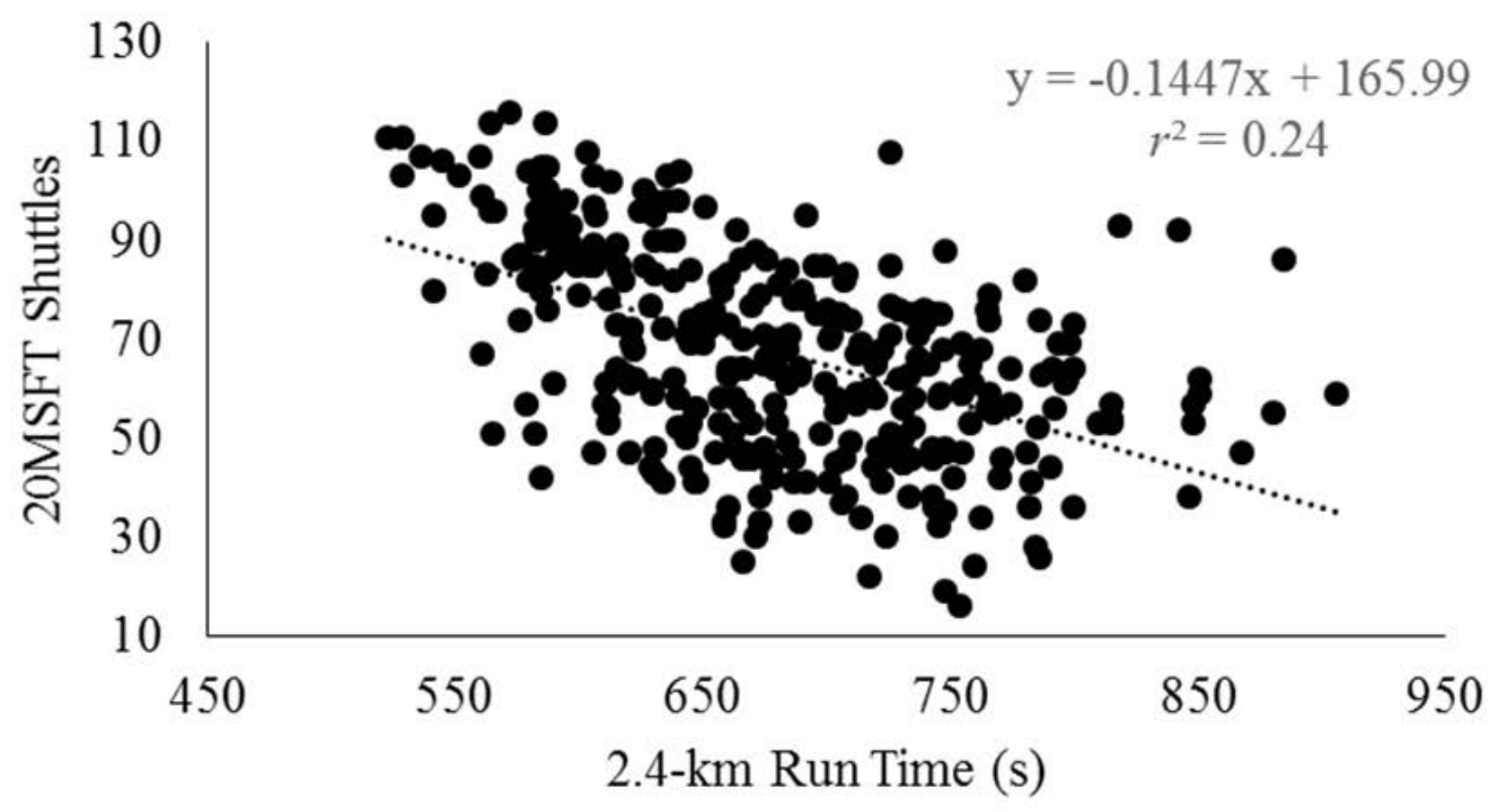




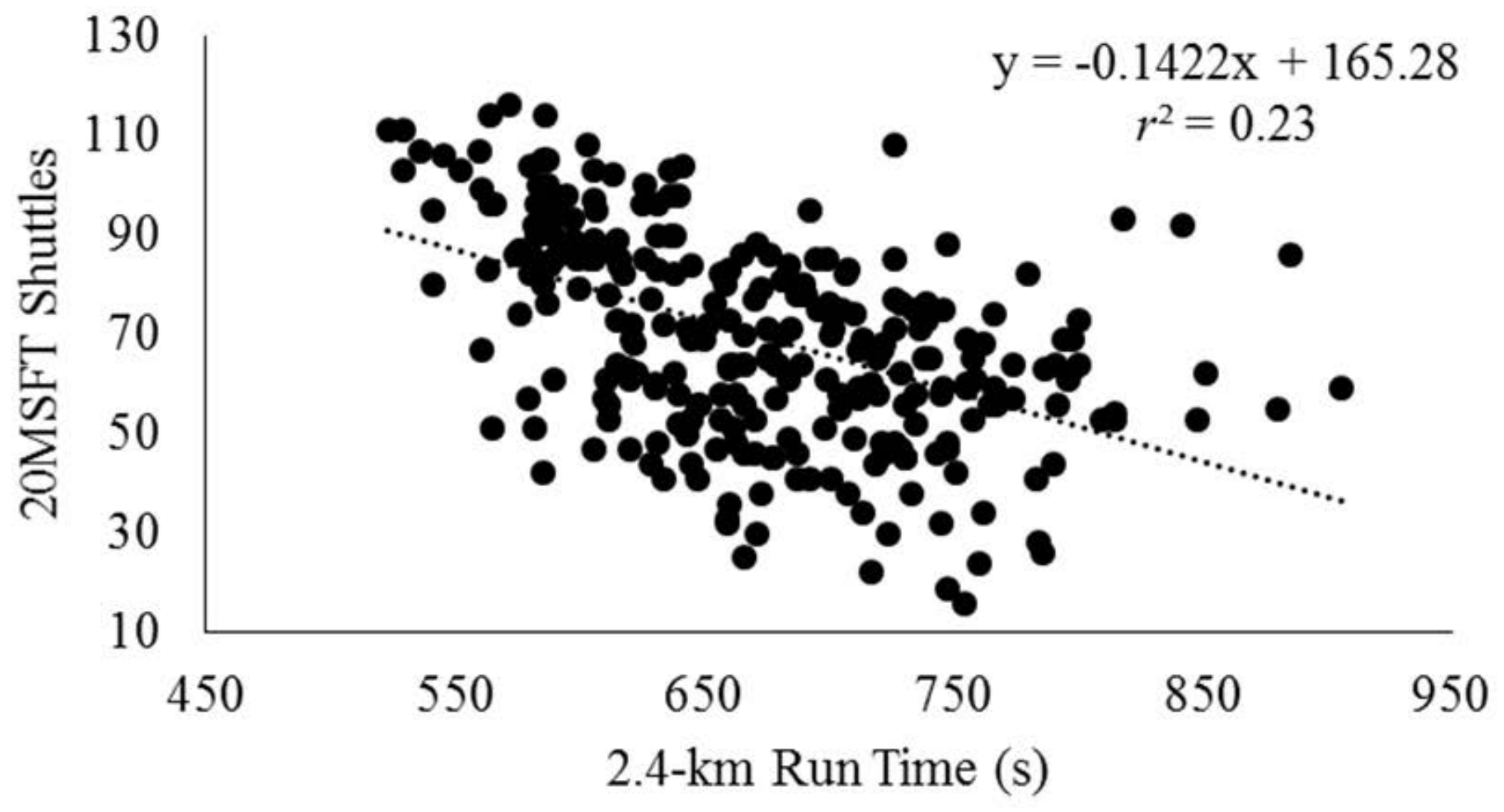




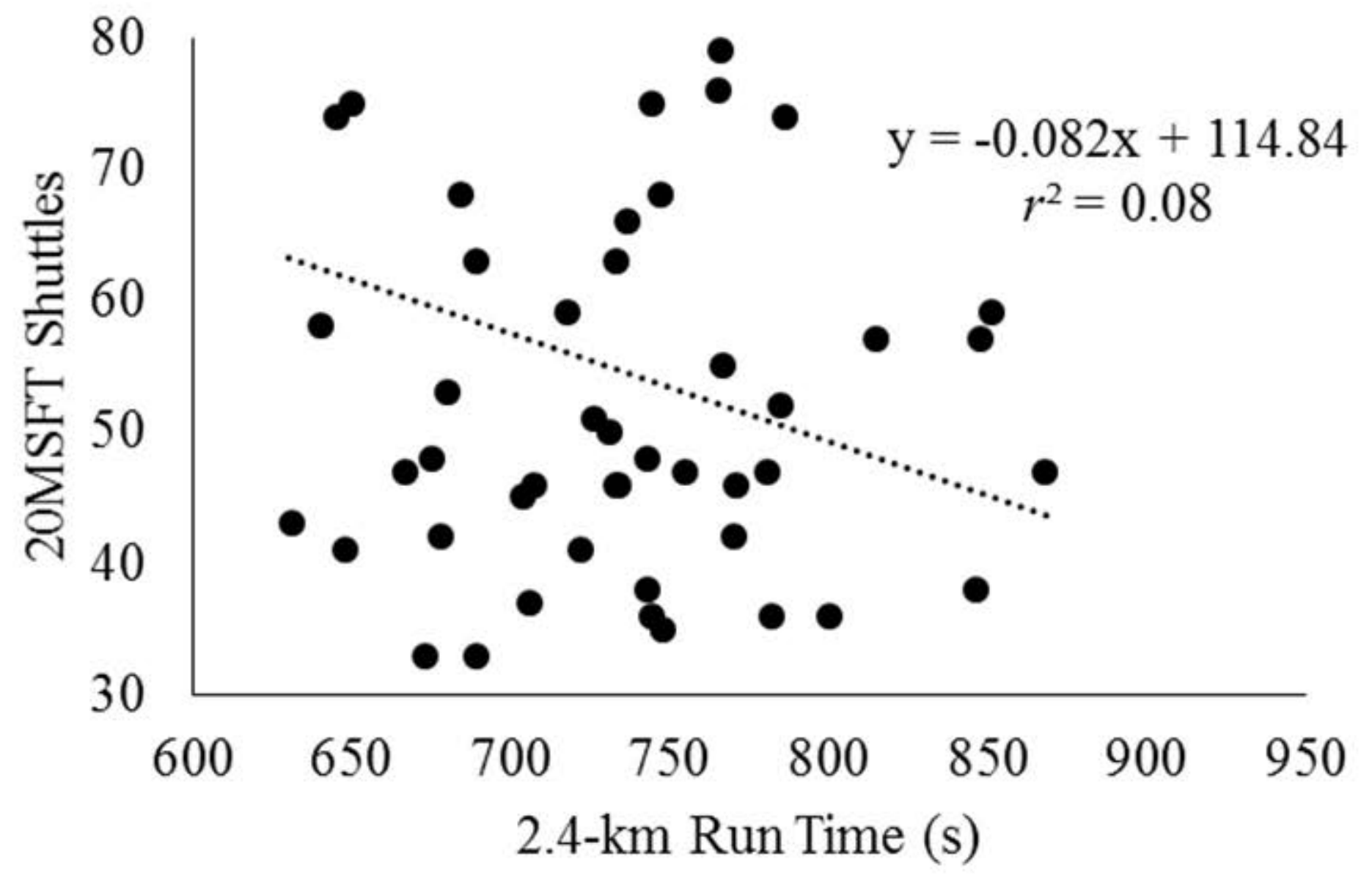

